\title{
Ultrastructural Changes of Human Dentin After Irradiation by Nd:YAG Laser
}

\author{
Bor Shiunn Lee, DDS, Ms, ${ }^{1,2}$ Chun Pin Lin, DDs, MS, PhD, ${ }^{1,2}$ Feng Huei Lin, PhD, 3 \\ and Wan Hong Lan, DDS, PhD $^{1,2 *}$ \\ ${ }^{1}$ Department of Dentistry, National Taiwan University Hospital, Taipei 10016, Taiwan \\ ${ }^{2}$ Department of Endodontics, School of Dentistry, College of Medicine, National Taiwan University, \\ Taipei 10016, Taiwan \\ ${ }^{3}$ Institute of Biomedical Engineering, College of Medicine, National Taiwan University, Taipei 10016, Taiwan
}

Background and Objective: The use of Nd:YAG laser has been proposed for endodontic treatment. However, its ability to reduce dentin permeability, which is important for the success of root canal treatment, remains controversial. Study Design/Materials and Methods: Nd:YAG laser irradiation was performed in pulsed mode on human dentin. The parameters were: pulse energy (100 mJ), rate (10 pps), and total irradiation time (4 seconds). The crystalline phases, electron diffraction patterns, morphology, and microstructure of specimens after laser irradiation were observed by dark-field emission transmission electron microscope (TEM).

Results: Three ultrastructural zones could be delineated in the dentin: (1) an outer zone with an ordered columnar structure composed of hydroxyapatite and $\beta$-tricalcium phosphate, (2) an intermediate zone composed of an amorphous substance (about 40-70 $\mathrm{nm}$ in diameter), and (3) an inner zone of well-crystallized hydroxyapatite grains. These three zones were free of pores or voids.

Conclusions: Our study demonstrated that laser-irradiation might be used to reduce dentin permeability. Lasers Surg. Med. 30:246-252, 2002. (c) 2002 Wiley-Liss, Inc.

Key words: crystalline changes; dentin permeability; Nd:YAG laser

\section{INTRODUCTION}

Dentinal tubules are the major channels for fluid flow across the dentin. When dental caries proceed near the pulp, reparative dentin formation beneath the carious lesion will obstruct the dentinal tubules to reduce dentin permeability and concentration of irritants. In dentin hypersensitivity, when the dentinal tubules are occluded [1], the hypersensitivity will be lessened by decrease of dentin permeability. Therefore, decrease of dentin permeability has long been the research interest in endodontics.

The laser has been proposed as an aid to conventional endodontic therapy. It can remove the smear layer of canal wall [2] and seal the exposed dentinal tubules [3,4]. However, data in the literature conflict about how laser irradiation can alter dentin permeability. If laser irradiation could fuse or glaze by melting the surface of dentin, and thereby, cause re-crystallization, the permeability of dentin could be decreased [5-7].

On the other hand, laser irradiation has been observed to increase dentin permeability. In this case, alteration of the physical structures (including crack formation, nonuniform glazing of the smear layer leaving dentinal surface porous, and organic material vaporization) was the leading reason for increased permeability [8-11].

The application of Nd:YAG laser for the reduction of dentin permeability in apicoectomy had also been reported with different results. Some studies demonstrated that laser treatment on resected root surfaces could cause melting and sealing of exposed dentinal tubules, and thus significantly reduce the permeability (dye penetration) of dentin [12-14]. Others showed that laser had no effect on reducing the bacterial leakage at the apical site [15].

Fayad et al. [16] evaluated the effects of $\mathrm{CO}_{2}$ laser irradiation on dentinal impedance by passing known cyclic potentials across dentinal wafers mounted as a window in an electrolytic cell and measuring the resulting electrical impedance. They reported that laser irradiation might yield temporary clinical relief from dentin hypersensitivity. Further investigation is necessary to determine the thermally induced changes in dentin structure, including the crystal structure.

Different types of lasers, operational modes, and energy outputs have been used. However, the most popular types recently used in preventive dentistry are the $\mathrm{CO}_{2}$ laser and $\mathrm{Nd}$ :YAG laser. In current clinical application, $\mathrm{CO}_{2}$ laser cannot be directed through a flexible optical fiber. On the other hand, the normal pulsed Nd:YAG laser is more suitable for clinical use and its applications to dentistry have been investigated for a long time. Studies have suggested that Nd:YAG laser may function as an alternative or adjunctive therapy in the control and treatment

Grant sponsor: National Science Council of Taiwan, Republic of China; Grant number: NSC 89-2314-13-002-365.

*Correspondence to: Wan Hong Lan, DDS, PhD, School of Dentistry, College of Medicine, National Taiwan University, No. 1, Chang-Te Street, Taipei 10016, Taiwan, R.O.C.

E-mail: whlan@ha.mc.ntu.edu.tw

Accepted 7 December 2001

Published online in Wiley Interscience

(www.interscience.wiley.com). DOI 10.1002/lsm.10038 
hypersensitivity [17-19]. An understanding of the morphological, crystal, and phase changes of dentin after laser treatment is essential to defining the clinical applications of lasers.

The purpose of this study was to characterize the morphological, crystal, and phase changes by high-resolution transmission electron microscopy when dentin was subjected to Nd:YAG laser irradiation.

\section{MATERIALS AND METHODS}

\section{Specimens Preparation}

Extracted human molars were used for this study. Crowns with caries, restorations, and cracks were discarded. Any remaining soft tissue was removed from the tooth surface by a dental scaler (Sonicflex 2000, KaVo Co., Biberbach, Germany). All teeth were then stored until used in $4^{\circ} \mathrm{C}$ distilled water containing $0.2 \%$ thymol to inhibit microbial growth.

The crowns were cut perpendicular to the long axis of the teeth with a diamond wafering blade mounted on a low-speed saw under water spray (Isomet; $10.2 \mathrm{~cm} \times$ $0.3 \mathrm{~mm}$, arbor size $1 / 2$ inch, series $15 \mathrm{HC}$ diamond; Buehler Ltd., Lake Bluff, IL). The enamel of each tooth was removed, and a dentin block with an area of about $3 \times 3 \mathrm{~mm}^{2}$ was shaped with a plain-cut tungsten carbide fissure bur at high speed under a continuous water spray.

\section{Laser Treatment}

The Nd:YAG laser (Contaclase DCL-8, SLT Co., Tokyo, Japan) that provided a constant beam of coherent, continuous monochromatic light with an emission wavelength of $1064 \mathrm{~nm}$ was used in this study. All specimens were randomly divided into two groups (A and B). In group A, the parameters of laser irradiation were: pulse energy $(100 \mathrm{~mJ})$, pulse rate (10 pps), and total time of irradiation (4 seconds). Each pulse duration was 100 microseconds. These parameters were used clinically in root canal treatment. Group B received no laser treatment and served as a control. The laser beam was focused $(1 \mathrm{~mm}$ from target surface) and delivered through the specific SLT $400-\mu \mathrm{m}$ bare fiber held in a straight handpiece.

\section{Materials Analysis}

The crystalline phases, morphology, and ultrastructure of specimens after laser irradiation were observed by a dark-field emission transmission electron microscope (TEM). The specimens used for TEM were obtained from a massive sample by slicing with a diamond blade saw. The slices were polished with diamond abrasives to a thickness of $30 \mu \mathrm{m}$ on a dimple grinder and then thinned by an ionbeam thinner. The ultrastructure of these specimens was investigated by an optical microscope (OM) (Nikon AFxIIA) and TEM, (Hitachi-HF-2000 scanning transmission electron microscope [STEM]) operating at $200 \mathrm{kV}$. Selected areas of electron diffraction patterns were recorded by photographic plates. A double tilt holder was used to reorient crystals in selected areas of the diffracting specimen. The calculation of the structural factor, the determination of diffraction patterns, and the measurement of angles between directions and interplanar spacing were manually calculated.

\section{RESULTS}

The TEM photographs of the laser-irradiated dentin indicated that lasing had resulted in significant ultrastructural changes. The photograph in Figure 1 showed the ultrastructure of dentin treated by Nd:YAG laser, using $10 \mathrm{pps}$ and $100 \mathrm{~mJ} /$ pulse of energy output for 4 seconds. The picture could be obviously divided into three zones from outer region to inner side. This phenomenon existed in all areas irradiated by the Nd:YAG laser. Inner zone was the area adjacent to laser exposure. The outer zone of about $20 \mathrm{~nm}$ in width was a row of well-crystallized area like a palisade, which was over the whole outer region. At higher magnification as shown in Figure 2, an orderly arrangement of dense columnar structures could be observed. The direction of preferred orientation was [002] of HAP, which could be analyzed by the diffraction pattern. The corresponding diffraction pattern was shown in Figure 3 that was consisted by hydroxyapatite (HAP) and $\beta$-tricalcium phosphate ( $\beta$-TCP) with a very small columnar structure. HAP was the major crystal of the

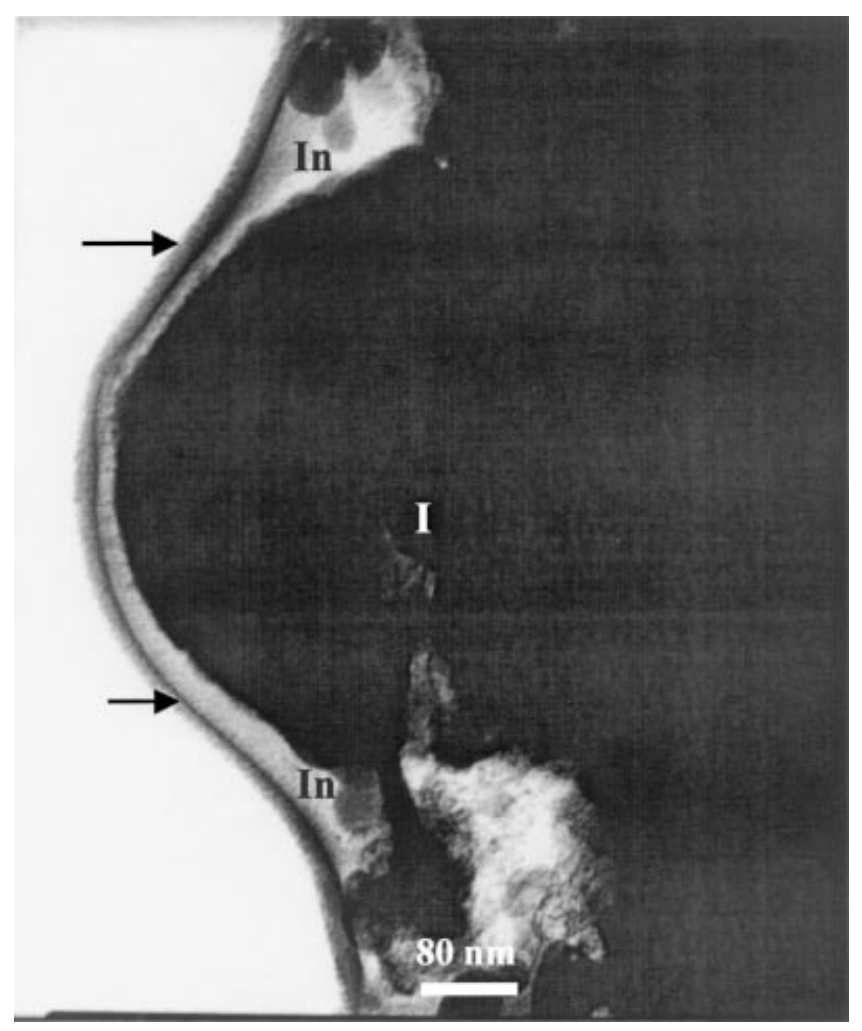

Fig. 1. After being exposed to Nd:YAG laser, the dentin showed a three-zone structure from outer region to inner side (I: inner zone, In: intermediate zone, arrow: outer zone). The exposure of laser beam was perpendicular to the adjacent area of inner zone. Outer zone was the area apart from the irradiation site and inner zone was the area near the irradiation site. 


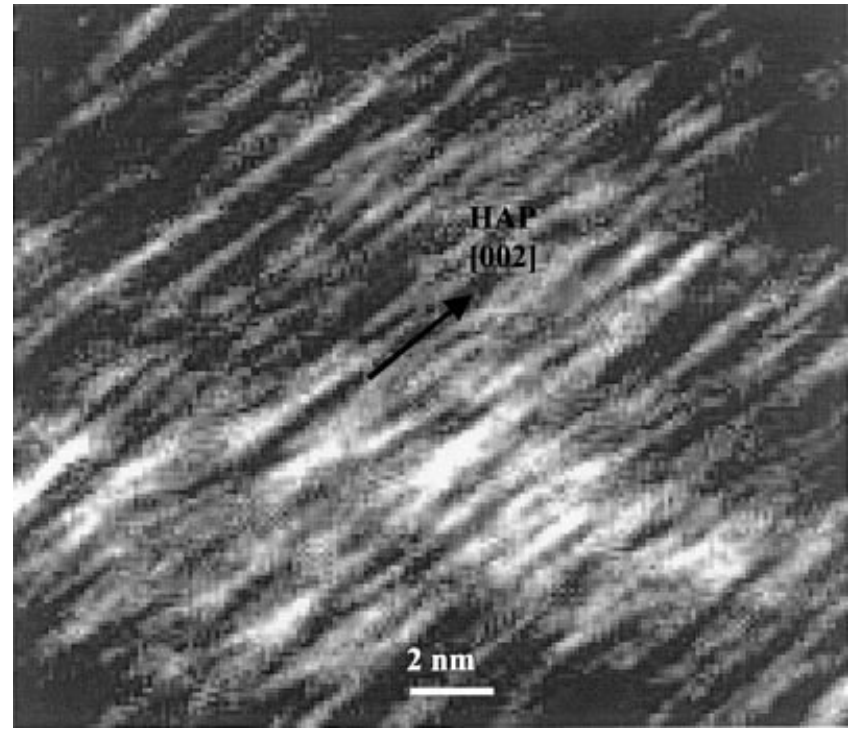

Fig. 2. A row of HAP crystals with columnar structure and preferred in HAP [002] orientation was over the whole outer zone.

outer zone with a distinct diffraction points in the pattern, which was identified as [130] zone as shown in Figure 3a. $\beta$-TCP was the minor phase with a small and less bright spots in the pattern due to its small amount, which was identified as [0ㅌ1] zone (Fig. 3b). If selected a larger area, the ring pattern with many rings (Fig. 4) was identified as HAP and $\beta$-TCP, respectively. The two phases were free of defect or pores and had well-defined lattice fringes indicating a regular crystalline structure. The width of this recrystallization band was about $20 \mathrm{~nm}$.

The intermediate zone consisted of an amorphous substance (about 40-70 $\mathrm{nm}$ in width) (Fig. 5). The selected area diffracted pattern was shown in Figure 6. There were no clear spots or rings present in the pattern. According to Bragg's Law $\lambda=2 \mathrm{~d}_{(\mathrm{hkl})} \sin \theta$, one interplanar spacing in a crystal lattice should be corresponding to a diffraction beam if it is fulfilled the requirement of Bragg's Law. Figure 6 shows a blurry and broadened ring pattern that reflected an amorphous structure without any crystals in the intermediate zone.

The inner zone was the place adjacent to the irradiation site. Large and well-crystallized grains with a sharp and distinct grain boundary occupied the inner zone as shown in Figure 7, where the crystals were identified as HAP in Figure 8 . The crystals were along the axis of [002]. There were a few small crystals inside a big crystal. These dentin crystals were devoid of inter- and intra-crystalline voids and the prism boundaries could be clearly distinguished. We could examine an inclined grain boundary with two beam dynamical condition in one grain and kinematical conditions in the other, which has very large spacing on all reflection. Such a boundary was visible as fringes with the same spacing as thickness fringes (Fig. 9). The possible mechanism for such fringes generation could be shown in Figure 10 [20]. It was important to realize that progressive
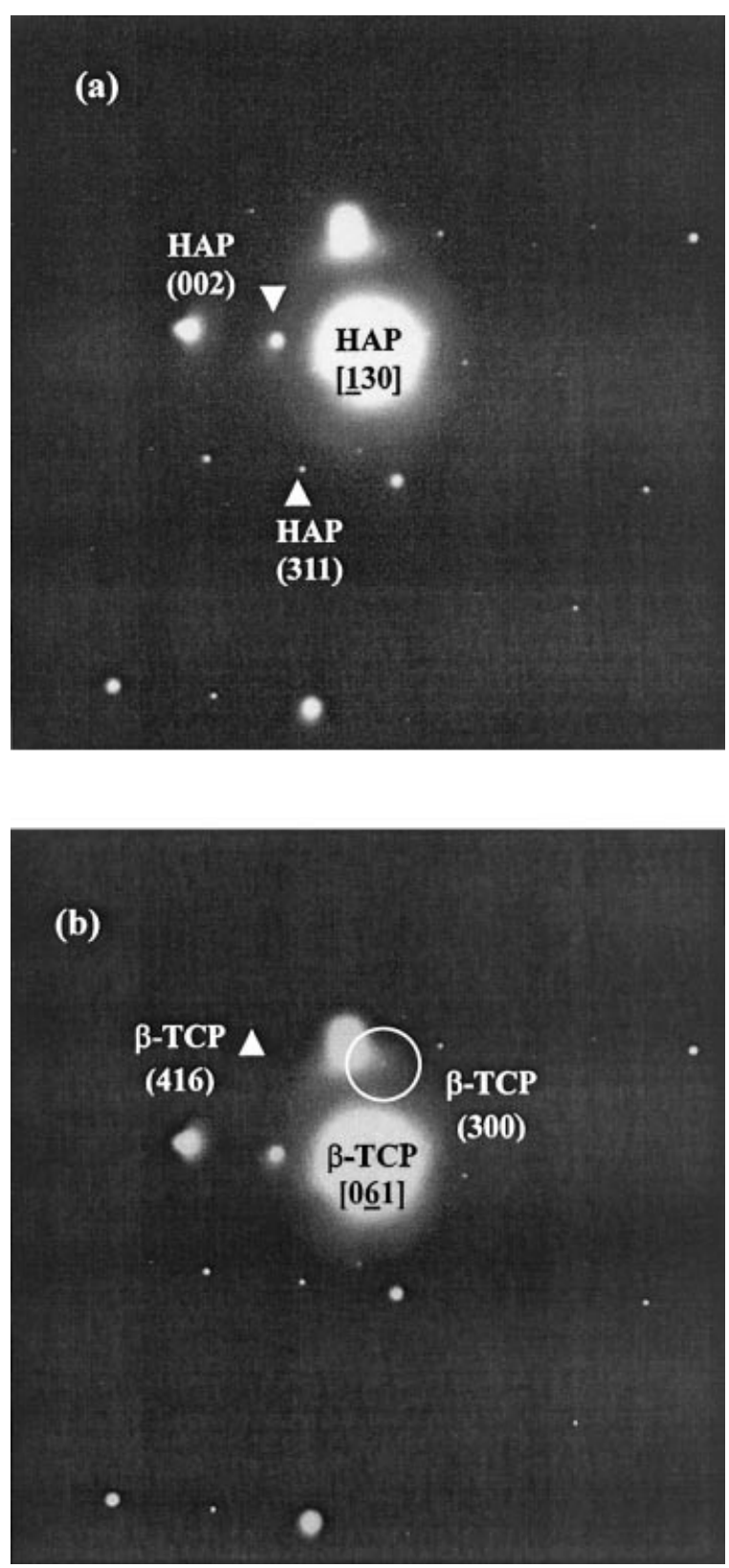

Fig. 3. The corresponding diffraction pattern consisted of (a) HAP and (b) $\beta$-traicalcium phosphate ( $\beta$-TCP) (circle: $\beta$ TCP (300), arrowhead: $\beta$-TCP (416)).

surface to roughening might occur if glancing angles of incidence were used for long periods, because surface bumps created "shadow regions", which the ion beam did not reach. Under some circumstances, if incident angles greater than $30^{\circ}$ were used during the early stage of thinning, a slightly uneven surface was produced (Fig. 10). Although the crystal size was not as large as that in enamel, the lattice fringes indicated a regular structure.

The morphology of nonirradiated dentin was shown in Figure 11. A well-crystallized grain with distinct grain boundary could be examined. But the average grain size 


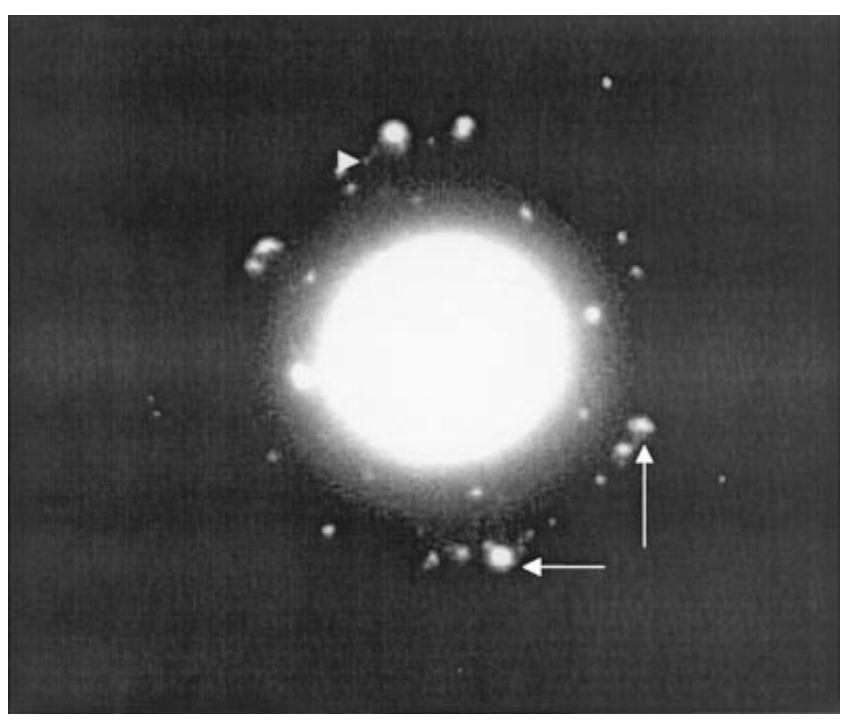

Fig. 4. If selected a larger area on Figure 2, the ring pattern with many rings was identified as HAP (002) (arrow) and $\beta$-TCP (300) (arrowhead), respectively.

was not as large as that of inner zone. These crystals were identified as HAP and located in the [400] zone according to the electron diffraction pattern (Fig. 12).

\section{DISCUSSION}

The changes reported in dentin permeability after $\mathrm{Nd}$ :YAG laser irradiation have been conflicting. In the present study, when the dentin surface was irradiated with the appropriate magnitude of laser energy, there was no formation of cracks at all. The Nd:YAG laser irradiation

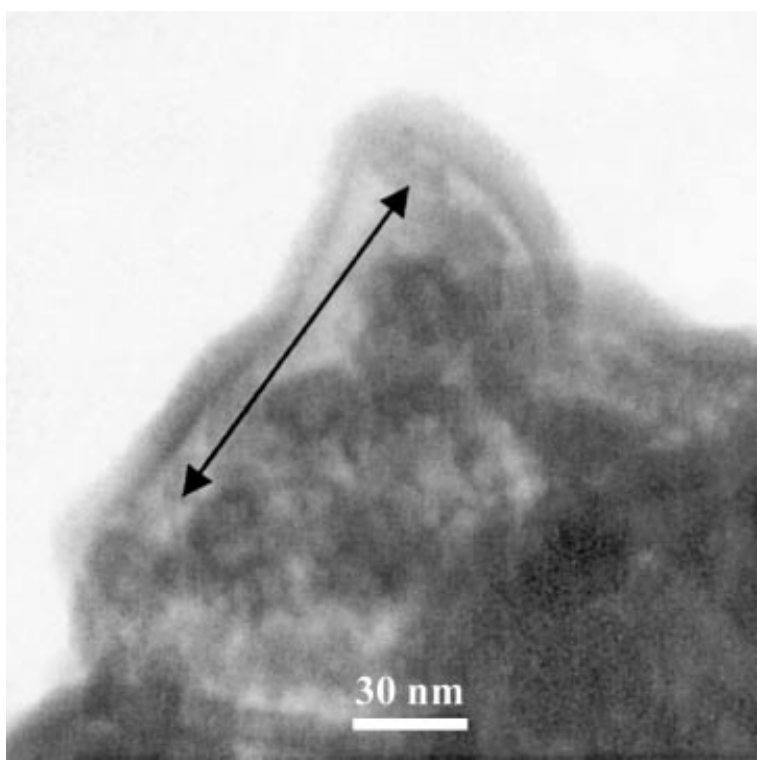

Fig. 5. The intermediate zone was about $40-70 \mathrm{~nm}$ in width, and composed of an amorphous substance (arrow).

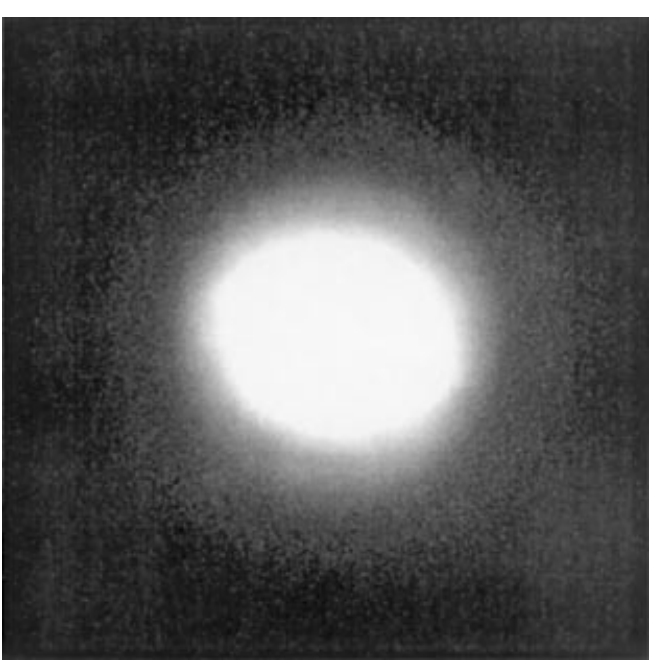

Fig. 6. By electron diffraction analysis, the pattern showed a blurry and broaden ring pattern that reflected an amorphous structure without any crystals in the intermediate zone.

could cause the melting and recrystallization of dentin [5]. Around the area being treated by Nd:YAG laser, a gradient of temperature was found during irradiation. The cooling rate of HAP after laser irradiation could be very

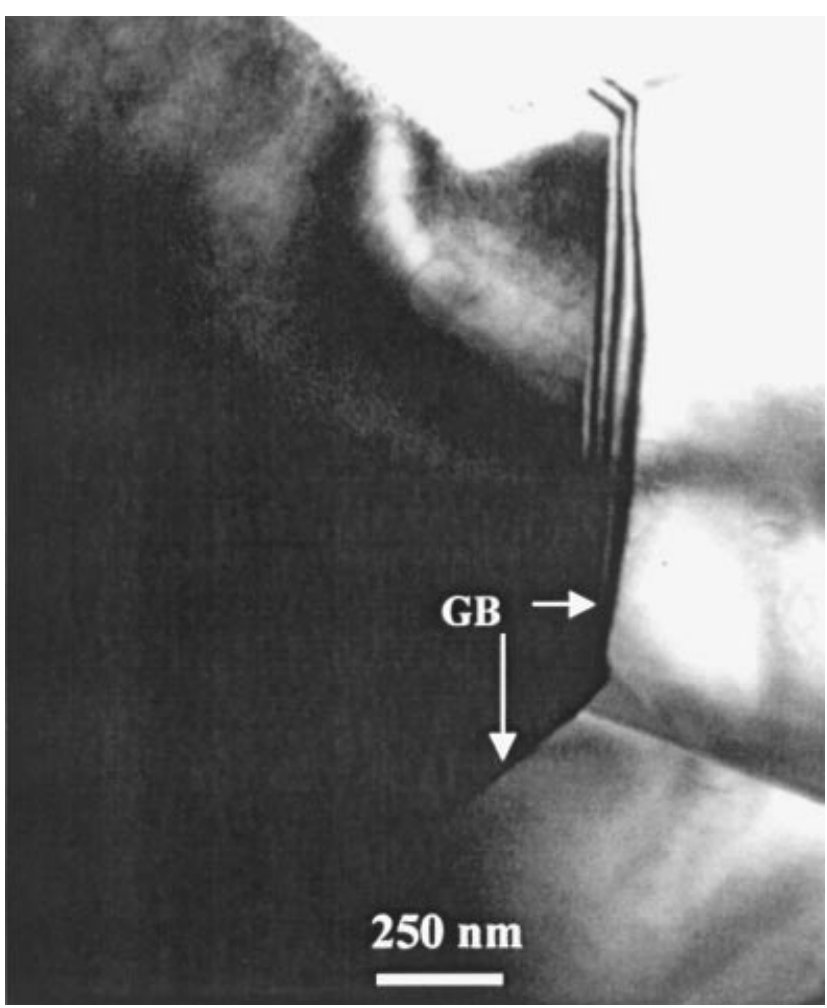

Fig. 7. Large and well-crystallized grains with a sharp and distinct grain boundary (GB) occupied the inner zone of the irradiated dentin. 


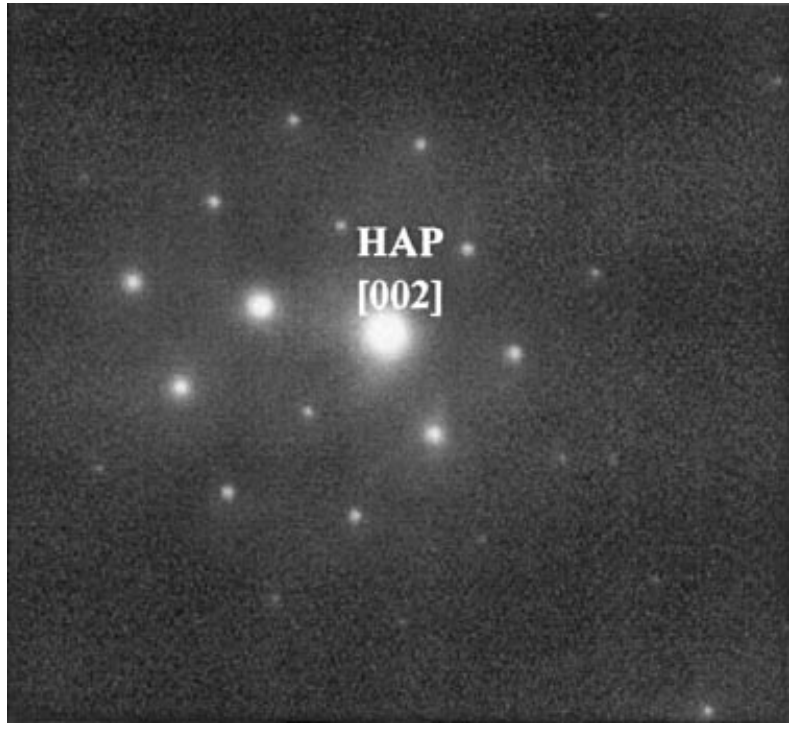

Fig. 8. The crystals on Figure 7 were identified as HAP by electron diffraction analysis.

rapid, and thus led to the formation of noncrystalline or metastable crystalline products [21].

In this study, three zones of dentin were observed after Nd:YAG laser irradiation. The outer zone was composed by very small grains with the columnar shape of HAP and

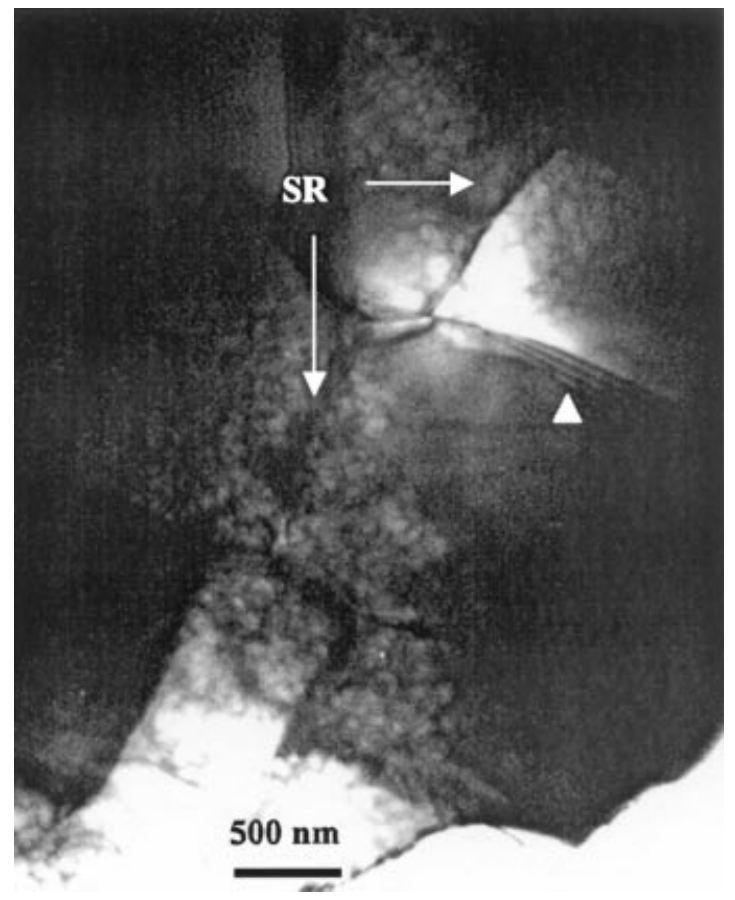

Fig. 9. A boundary was visible as fringes (arrowhead) with the same spacing as thickness fringes (SR: shadow regions). The fringe structure was generated from the shadow region between the grain boundaries that would be no harm to the dentin structure.

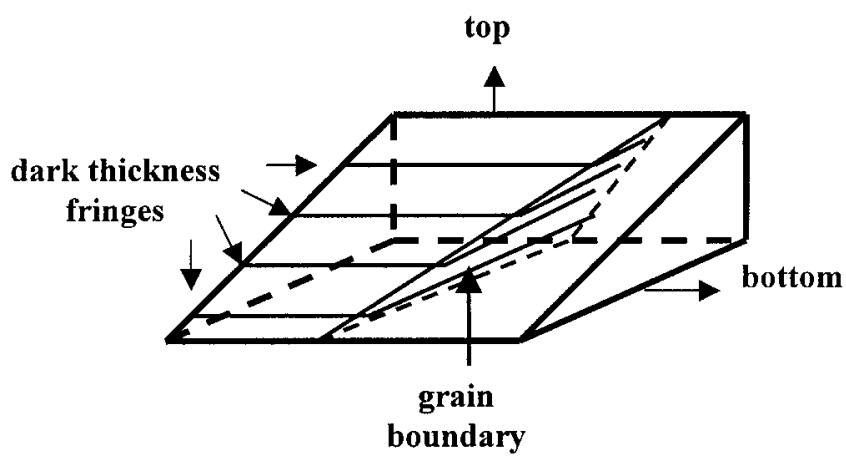

Fig. 10. A schematic diagram illustrated an inclined grain boundary in a wedge-shape region of a thin specimen.

$\beta$-TCP, where only $20 \mathrm{~nm}$ in width (Fig. 1). After being exposed to the laser, the outer zone of the dentin should be melted. Once the laser was removed, the outermost zone of the dentin was in contact with the air, resulting in the formation of many nucleation sites around the interface between dentin and air. This contact led to the generation of columnar-shaped crystals at the interface of the outer zone (Fig. 2). As coated HAP onto the surface of the metal substrate, which would be heated to a very high temperature (usually over $10,000^{\circ} \mathrm{C}$ ), it would lead to the formation of non-crystalline or metastable crystalline products such as oxyHAP (OHAP, $\mathrm{Ca}_{10}\left(\mathrm{PO}_{4}\right)_{6}(\mathrm{OH})_{2-\mathrm{x}} \mathrm{O}_{\mathrm{X}} \square \mathrm{x}$ ), $\alpha$-tricalcium phosphate $\left(\alpha-\mathrm{TCP}, \mathrm{Ca}_{3}\left(\mathrm{PO}_{4}\right)_{2}\right)$, tetracalcium phosphate (TTCP, $\mathrm{Ca}_{4} \mathrm{P}_{2} \mathrm{O}_{9}$ ), calcium oxide $(\mathrm{CaO})$, and amorphous apatite in the HAP coating [22,23]. These phase (except HAP and $\beta$-TCP) were easily dissolved in a water-rich environment [24]. In addition, all the dissolved products would re-precipitate and turn into HAP via crystal reconstruction $[25,26]$. In this study, the phases of

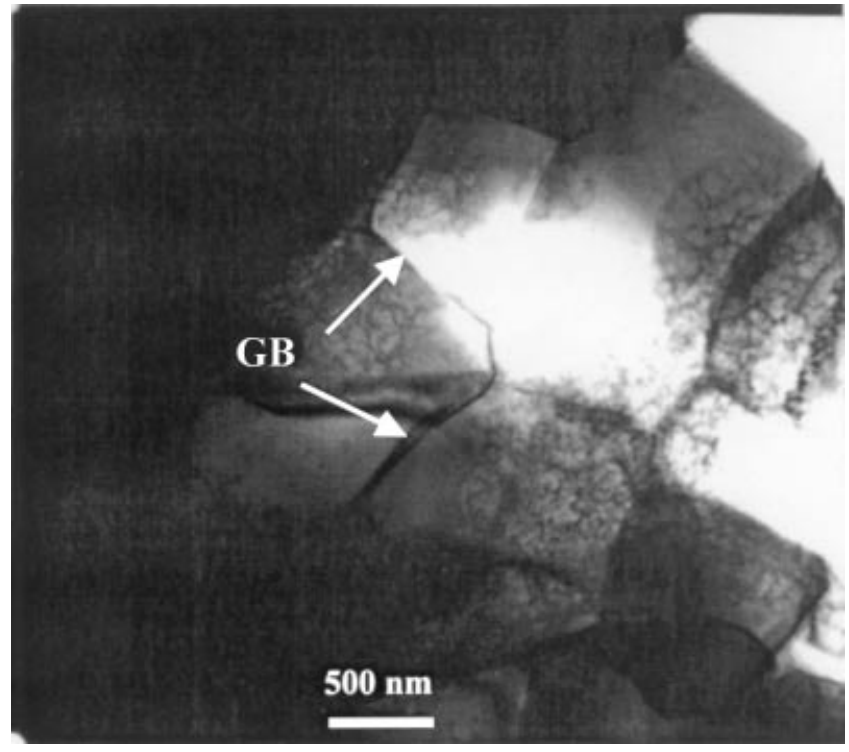

Fig. 11. The non-irradiated dentin showed well-crystallized grain with distinct GB. 


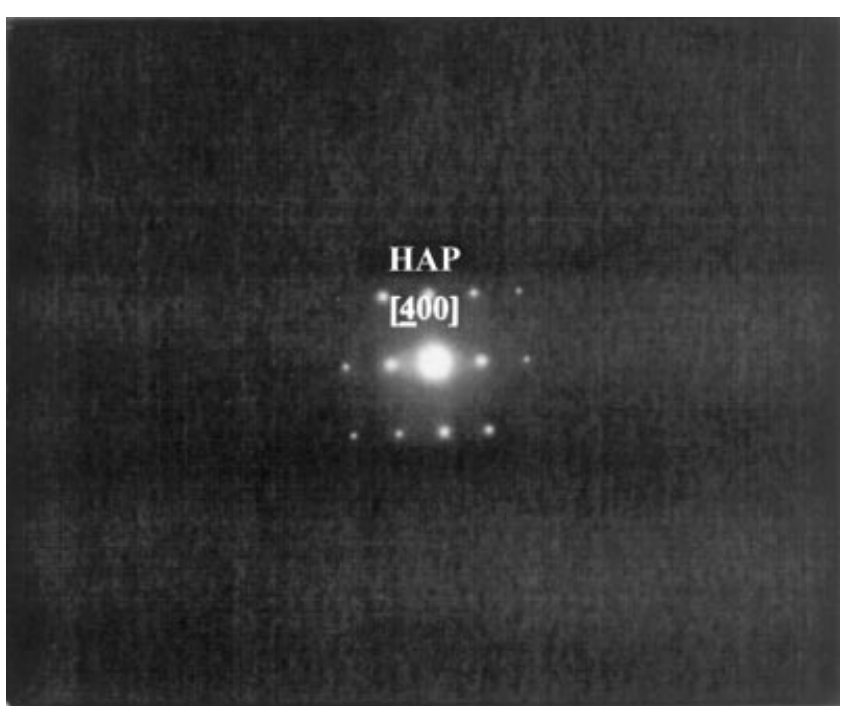

Fig. 12. The crystals on Figure 11 were identified as HAP and located in the (400) zone by electron diffraction analysis.

outer zone were mainly composed of HAP and trace amounts of $\beta$-TCP. These kinds of structures are stable in the oral environment. It was shown that the new crystal layer appeared as a palisade and surrounded the laser spot orderly. The organic substrate seemed to be vaporized away and there was not any cracks or voids. It was beneficial for the dentin to have its permeability reduced without the existence of microscopic cracks, voids, or columnar crystals on the outer zone.

By contrast, the intermediate zone was composed of amorphous substance (Figs. 5 and 6) as a result of being quenched at a high cooling rate without the formation of nucleation sites due to its lack of contact with the air. There was not enough time for it to re-crystallize. Many different microstructural features could serve as preferential nucleation sites. Some, like the wall of the mold that contains a liquid, are always present; others like a small piece of a ceramic crucible that may have broken off during the pouring of the molten metal into the mold, may be accidentally present. The energy barrier for heterogeneous nucleation is always lower than that for homogeneous nucleation. The energy release by the elimination of any defect acting as a nucleation site can be used to reduce the energy needed for nucleation in the absence of that defect.

The inner zone was composed of large crystals (Fig. 7) due to thermal effect of laser irradiation. Re-crystallization with formation of a large grain could be explained as follows. Since HAP in the dentin was melted under $\mathrm{Nd}$ :YAG laser exposure, the liquid phase in the inner zone was covered by the outer and intermediate zones; these zones kept the liquid from contacting the outer environment. The melted material was solidified at a moderate cooling rate, which led to the crystal growth under a steady-state condition, which produced a larger HAP grain. Moreover, part of the melted material penetrated the dentin structure where grain growth and coalescence may have occurred due to liquid phase sintering. Densification and growth of the solid particles in the liquid phase sintering could be divided into three steps [27,28]:

1. On formation of a liquid phase, there was a rearrangement of particles to give effective packing.

2. Further densification and growth of particles of the solid phase were achieved by solution and a re-precipitation and coalescence process.

3. Prolonged compacting at the sintering temperature might lead to further growth of the particles and formation of an ordered arrangement of the solid phase. The formation of new crystals around the laser spot in this study could be deduced from the mechanism mentioned above.

Since crystallization was accomplished by subjecting suitable matrix to a carefully regulated heat-treatment schedule, which resulted in the nucleation and growth of crystal phases within the matrix, the amorphous substance of the intermediate layer was formed as a result of the high cooling rate.

The discrete crystals of the inner zone had a different size and did not appear to have an ordered arrangement. The reason was that the transformation proceeded from distinct centers and crystal growth took place by deposition of material upon the first tiny crystals or nuclei. If the re-arrangement rate into the periodic lattice of the growing crystal was high, then the crystal size became larger.

The Nd:YAG laser is used in a contact mode when sapphire tip is attached. In this study, we used the silica fiber instead of sapphire tip, and thus positioned the tip $1 \mathrm{~mm}$ from the specimen. If the fiber tip is positioned to contact the specimen, the vaporized dentin will contaminate the fiber tip. This will lead to the reduction of the energy output from our previous setting. Thus, we kept the fiber tip $1 \mathrm{~mm}$ from the specimen surface.

The decrease of dentin permeability is important in endodontics. In dentin hypersensitivity, the blocking of the exposed dentin is a solution. Once the laser can reduce the dentin permeability, it can lessen the severity of the symptoms. Our clinical experience also supports that the Nd:YAG laser is a useful tool in the treatment of dentin hypersensitivity [18]. In dental caries, an inflammatory reaction develops in the pulp before the pulp is actually infected [29]. This indicates that bacterial products reach the pulp in advance of the bacteria. The open tubules may allow bacterial penetration, causing failure of treatment. If the Nd:YAG laser can cause sealing of dentinal tubules [17] and reduce the dentin permeability. It can decrease the concentration of the irritants and preserve the health of the pulp.

Though the organic substance was vaporized during laser irradiation, the dentin was free from voids or porosity. It was due to recrystallization and grain coalescence. At the appropriate energy level, the irradiation did not cause porosity to develop because the overall volume changes were very small. The absence of pores in dentin is also a benefit because pores will reduce mechanical 
strength and may act as flaws at which internal fractures could originate. From our study, the dentin after Nd:YAG laser irradiation demonstrated a three-zone structure. The outer zone composed by HAP and $\beta$-TCP showed an orderly columnar structure. The intermediate zone was a homogenous glass phase. The inner zone with grain growth and well-crystallized prism could be examined. All three zones showed a microstructure without pores and voids. Thus, the energy output with $100 \mathrm{~mJ}-10 \mathrm{pps}-4 \mathrm{sec}$ might reduce the permeability of dentin.

\section{REFERENCES}

1. Pashley DH, Livingston MJ, Reeder OW, Horner J. Effects of the degree of tubule occlusion on the permeability of human dentine in vitro. Archs Oral Biol 1978;23(12):1127-1133.

2. Anic I, Tachibana H, Matsumoto K. Permeability, morphologic and temperature changes of canal dentine walls induced by Nd:YAG, $\mathrm{CO}_{2}$ and argon lasers. Int Endod J 1996;29:13-22.

3. Sánchez F, España Tost AJ, Morenza JL. ArF excimer laser irradiation of human dentin. Lasers Surg Med 1997;21:474479.

4. Moritz A, Gutknecht N, Goharkhay K, Schoop U, Wernisch J, Sperr W. In vitro irradiation of infected root canals with a diode laser: Results of microbiologic, infrared spectrometric, and stain penetration examinations. Quintessence Int 1997;28:205-209.

5. Dederich DN, Zakariasen KL, Tulip J. Scanning electron microscopic analysis of canal wall dentin following Neodymium Yittrium-Aluminum-Garnet laser irradiation. J Endodon 1984;10:428-431.

6. Goodis HE, White JM, Marshall JR GW, Yee K, Fuller N, Gee L, Marshall SJ. Effects of Nd: and Ho:Yttrium-AluminiumGarnet lasers on human dentine fluid flow and dental pulpchamber temperature in vitro. Archs Oral Biol 1997;42:845854.

7. Miserendino LJ, Levy GC, Rizoiu IM. Effects of Nd:YAG laser on the permeability of root canal wall dentin. J Endodon $1995 ; 21: 83-87$.

8. Pashley EL, Horner JA, Liu M, Kim S, Pashley DH. Effects of $\mathrm{CO}_{2}$ laser energy on dentin permeability. J Endodon 1992; 18:257-262.

9. Tewfik HM, Pashley DH, Horner JA, Sharawy MM. Structural and functional changes in root dentin following exposure to KTP/532 laser. J Endodon 1993;19:492-497.

10. Pashley DH, Stewart FP, Galloway SE. Effects of air-drying in vitro on human dentin permeability. Arch Oral Biol 1984;29:379-383.

11. Schaller HG, Weihing T, Strub JR. Permeability of dentine after Nd:YAG laser treatment: An in vitro study. J Oral Rehabil 1997;24:274-281.
12. Stabholz A, Khayat A, Ravanshad SH, McCarthy DW, Neev J, Torabinejad M. Effects of Nd:YAG laser on apical seal of teeth after apicoectomy and retrofill. J Endodon 1992;18: 371-375.

13. Stabholz A, Neev J, Liaw HL, Khayat A, Torabinejad M. Sealing of human dentinal tubules by $\mathrm{XeCl} 308-\mathrm{nm}$ excimer laser. J Endodon 1993;19:267-271.

14. Arens DL, Levy GC, Rizoiu IM. A comparison of dentin permeability after bur and laser apicoectomies. Compend Contin Educ Dent 1993;10:1290-1297.

15. Wong WS, Rosenberg PA, Boylan RJ, Schulman A. A comparison of the apical seals achieved using retrograde amalgam fillings and the Nd:YAG laser. J Endodon 1994;20: 595-597.

16. Fayad MI, Carter JM, Liebow C. Transient effects of lowenergy $\mathrm{CO}_{2}$ laser irradiation on dentinal impedance: Implications for treatment of hypersensitive teeth. J Endodon 1996; 22:526-531.

17. Lan WH, Liu HC. Sealing of human dentinal tubules by Nd:YAG laser. J Clin Laser Med Surg 1995;13:329-333.

18. Lan WH, Liu HC. Treatment of dentin hypersensitivity by Nd:YAG laser. J Clin Laser Med Surg 1996;14:89-92.

19. Liu HC, Lin CP, Lan WH. Sealing depth of Nd:YAG laser on human dentinal tubules. J Endodon 1997;23:691-693.

20. Edington JW. Interpretation of transmission electron micrographs. In: Practical Electron Microscopy in Materials Science. East Kilbride, Scotland: Thomson Litho Ltd. 1985: 53.

21. Zyman Z, Weng J, Liu X, Li X, Zhang X. Phase and structural changes in hydroxyapatite coating under heat treatment. Biomaterials 1994;15:151-155.

22. Lin FH, Liao CJ, Chen KS, Sun JS. Thermal reconstruction behavior of the quenched hydroxyapatite powder during reheating in air. Mater Sci Eng C 2000;13:97-104.

23. Lin CP, Lin FH, Tseng YC, Lee BS, Lan WH. Treatment of tooth fracture by medium energy $\mathrm{CO}_{2}$ laser and DP-bioactive glass paste: Thermal behavior and phase transformation of human tooth enamel and dentin after irradiation by $\mathrm{CO}_{2}$ laser. J Mater Sci-Mater M 2000;11:1-9.

24. Ducheyne P, Radin S, King L. The effect of calcium phosphate ceramic composition and structure on in vitro behavior. I. Dissolution. J Biomed Mater Res 1993;27:25-34.

25. Liao CJ, Lin FH, Chen KS, Sun JS. Thermal decomposition and reconstitution of hydroxyapatite in air atmosphere. Biomaterials 1999;20:1807-1813.

26. Lin FH, Liao CJ, Chen KS, Sun JS. Preparation of a biphasic porous bioceramic by heating bovine cancellous bone with $\mathrm{Na}_{4} \mathrm{P}_{2} \mathrm{O}_{7} \cdot 10 \mathrm{H}_{2} \mathrm{O}$ addition. Biomaterials 1999;20:475-484.

27. Lenel FV. Sintering in presence of liquid phase. Trans AIME 1984;175:878-891.

28. Yoon DN, Huppmann WJ. Grain growth and densification during liquid phase sintering. Acta Met 1979;27:693-698.

29. Trowbridge HO. Pathogenesis of pulpitis resulting from dental caries. J Endodon 1981;7:52-60. 